\title{
Association of Significant Coronary Arterial Disease, Coronary Calcification and Carotid Intima Media Thickness with Glycosylated Hemoglobin Levels in Patients without History of Diabetes Mellitus Sent for Coronary CT Angiography Ahmed Adel Saber Taha \\ Cardiology Department, Faculty of Medicine, Ain Shams University \\ *Corresponding author: Ahmed Adel Saber Taha, E-mail: ahmed.adel28989@gmail.com, Mobile: (+20)01065453522
}

\begin{abstract}
Background: Diabetes mellitus (DM) is a risk factor for the development of the coronary heart disease (CHD), and individuals with DM have more extensive atherosclerosis, more cardiac events, and higher prevalence of silent ischemia as compared with individuals without DM.

Objective: The aim of the study is to assess the association of significant coronary arterial disease, coronary calcification and carotid intima media thickness with glycosylated hemoglobin levels in patients without history of diabetes mellitus sent for coronary CT angiography.

Patients and methods: This prospective study included 39 patients who underwent 320 Multi-slice CT coronary angiography (Aquilion ONE 320 MSCT) at (Nasr-City Police Hospital) through the period from May 2017 to April 2018. They divided into 3 equal groups according to HbA1c (G1, non-diabetic, G2, pre-diabetic and G3 diabetic). The study was approved by Ain Shams University academic and ethical committee and an informed written consent was obtained from all patients.

Results: At level of multi-slice CT coronary, CCS was significantly higher in Group C than in Group A and B. But no significant difference could be picked in subgroup analysis between Group A and Group B. There were no significant differences among groups as regarding significant coronary artery stenosis. But there was a trend towards significance in Group C; however, it failed to reach significance mostly because of the small sample size. At level of carotid Doppler US, there were significant differences between groups as regarding bilateral CIMT. But this significance was mainly between Group C and the other groups in subgroup analysis. As regarding correlation, age and HbAlc had a positive strong correlation with CCS, LT CIMT, and RT CIMT. Conclusion: HbAlc positively correlates with coronary and carotid atherosclerosis and patients with mild elevation of HbAlc has significantly more CIMT than individuals with normal HbAlc.
\end{abstract}

Keywords: DM, CAD, CHD, CT angiography, CIMT, HbAlc.

\section{INTRODUCTION}

For decades the diagnosis of diabetes mellitus was based on plasma glucose criteria, either fasting plasma glucose (FPG) or 2-hour value in the $75 \mathrm{~g}$ oral glucose tolerance test (OGTT) ${ }^{(1)}$. In 2009, an international expert committee, that included the representatives of the American Diabetic Association (ADA), the International Diabetes Federation (IDF) and the European Association for the Study of Diabetes (EASD) recommended the use of HbAlc test to diagnose diabetes, with threshold of $>6.5 \%$ and the ADA adopted this criterion in $\mathbf{2 0 1 0}{ }^{(2)}$.

Glycated hemoglobin, assessed clinically by $\mathrm{HbAlc}$, is a time integrated marker of average blood glucose concentration increasingly used in the screening and management of diabetes, and it is more closely related to the risk of complications than are single or episodic measures of glucose levels ${ }^{(3)}$. There is consistent evidence that $\mathrm{HbAlc}$ levels control results in lower incidence of micro vascular and macro vascular complications in both type 1 and type $2 \mathrm{DM}^{(4)}$.

The most common cause of death due to cardiovascular diseases is coronary artery disease (CAD), which is a progressive inflammatory disease with underlying atherosclerosis in its etiology. It is the end result of the accumulation of atheromatous plaques within the walls of the coronary arteries that supply the myocardium with oxygen and nutrients ${ }^{(5)}$.

Several tools can be used for the diagnosis of CAD. Among which Multi-Slice Computed Tomography (MSCT) that plays an important role as a non-invasive tool for assessing coronary atherosclerosis and diagnosing of CAD. Recent advances in MSCT technology have continuously improved the quality of non-invasive cardiac imaging. As a result, various studies have demonstrated a high accuracy of coronary angiography (CA) with 64-slice CT for the diagnosis of $\mathrm{CAD}^{(\boldsymbol{(})}$.

Prevalence and degree of intima media thickness in the carotid arteries has been related to risk factors for cardiovascular disease ${ }^{(7)}$.

The value of carotid artery disease in the prediction of severe coronary artery disease has been assessed in cohort studies of patients with suspected ischemic heart disease ${ }^{8)}$.

\section{AIM OF THE WORK}

The aim of the study was to assess the association of significant coronary arterial disease, coronary calcification and carotid intima media 
thickness with glycosylated hemoglobin levels in patients without history of diabetes mellitus sent for coronary CT angiography.

\section{PATIENTS AND METHODS}

The current study prospectively included 39 patients who underwent 320 Multi-slice CT coronary angiography (Aquilion ONE 320 MSCT) at (Nasr-City Police Hospital) through the period from May 2017 to April 2018.

Patients were subdivided into three groups according to their HbAlc level (1):

- Group 1 (Non-diabetics): 13 cases whose HbAlc $<5.7 \%$.

- Group 2 (Pre-diabetics): 13 cases whose HbAlc 5.7- 6.4\%.

- Group 3 (Diabetics): 13 cases whose HbAlc $>6.4 \%$.

Ethical consideration and Written informed consent :

An approval of the study was obtained from Ain Shams University academic and ethical committee. Every patient signed an informed written consent for acceptance of the operation.

\section{All the patients were subjected to the following: \\ History: \\ 1- With special emphasis on age, gender and major documented risk factors for coronary artery disease (HTN, DM, Smoking, DLP and Family history of CAD). \\ 2- Complaint including chest pain (character, duration, PPT factors and relation to effort) and dyspnea. \\ 3- Neurological symptoms e.g. Dizziness. \\ 4- Past history of CVS, TIAs.}

Complete clinical examination with special stress on:

1- Vital signs including blood pressure, temperature and respiratory rate.

2- Cardiac examination including heart rate and murmurs.

3- Chest examination

4- Extremities examination for edema and peripheral vascular disease.

\section{Electrocardiographic examination:}

With standard 12 leads ECG to examine for:

1- ST-T segment shift.

2 -Reversal of $T$ wave polarity

3- Pathological Q wave.

\section{Routine laboratory testing:}

- Renal function (blood urea nitrogen and creatinine level).
- Lipid profile: patients were instructed to remain fasting for 12 hours prior to the sample withdrawal.

- FBS: patients were instructed to remain fasting for 8 hours prior to the sample withdrawal

HbAlc:

- The sample was withdrawn and processed by Automated Glycohemoglobin Analyzer HLC-723G7.

- This method is based on the charge differences and the device is considered one of the modern instrumentations of tertiary hospital.

MSCT Angiography:

- The Aquilion ONE 320 Slice CT is the most advanced CT system in the market. This dynamic volume $\mathrm{CT}$ in comparison to a 64-Slice, 128-Slice or 256 slice CT scan can scan an entire organ in one single pass and produce $4 \mathrm{D}$ videos showing organ's structure, movement and blood flow. In addition, the system is fast enough to image the entire heart in less than a heartbeat, opening the door to accurate and safe imaging of patients with arrhythmia.

\section{Patient preparation:}

- Full clinical examination was carried out. The resting heart rate and blood pressure were recorded. Chest examination was done to rule out patients with reactive airways. Routine cardiac examination was carried out. The patient's lab investigations were reviewed especially serum creatinine. All patients were instructed to remain fasting for about 4 hours before doing the scan. Patients were instructed as well to avoid coffee and tea drinks 24 hours before the study, to minimize their effects on the patients' heart rate.

\section{Heart rate control:}

- The protocol depended on the resting heart rate of the patient. Patients with heart rate above $65 \mathrm{bpm}$ were given $50 \mathrm{mg}$ of Atenolol orally, half to one hour before the procedure, larger doses of Atenolol can be given if blood pressure and heart rate allow.

- Patients with a resting heart rate less than $60 \mathrm{bpm}$ didn't receive any beta blockers. A second dose of atenolol was given one hour after the initial one if the heart rate was not satisfactory (above $65 \mathrm{bpm}$ ) up to a maximum of $200 \mathrm{mg}$ as long as blood pressure permits. Some patients needed an additional bolus of intravenous propranolol (1-2 $\mathrm{mg}$ ), typically patients who showed an increased heart rate on the CT couch. 
- Anxious patients received an oral benzodiazepine, $1.5 \mathrm{mg} 15-30$ minutes before the scan. Scan protocol and data interpretation: After controlling the heart rate, the patients were transferred to the scanning room where he or she will lay on the CT couch. The full procedure was then explained to the patient. Breathing exercise was done to make sure the patient can hold his breath adequately. ECG electrodes were placed to connect the patient continuous ECG monitoring.

- An IV access was secured (preferably an $18 \mathrm{G}$ cannula). The preferred sites were the right antecubital vein, left ante-cubital vein then other sites, in order of preference. The patient will be then given a tablet of $5 \mathrm{mg}$ isosorbide dinitrate sublingually. The IV line was then connected to the dual head injector. When the patient was ready and after doing breathing exercise (and observing the heart rate response to the breath hold), the scan procedure was started.

- $\quad 50-70 \mathrm{ml}$ of contrast was then injected through the IV line using the dual head injector, followed by a $50 \mathrm{ml}$ of saline chaser. The injection rate was set at $5-6 \mathrm{ml} / \mathrm{sec}$ for both the contrast and the saline. The contrast used was a non-ionic iso-osmolar iodine containing contrast. ECG gated reconstructions was done in the best phase (either systolic or diastolic but preferably the diastolic phase). The whole coronary tree was reviewed for motion artifacts, if there were any, other phases of reconstruction were done including systolic phase. The datasets were reconstructed at a slice thickness of $0.6 \mathrm{~mm}$ with 0.3 $\mathrm{mm}$ increment.

\section{MSCT Coronary Angiography analysis:}

- The severity of luminal diameter will be scored as none (0\% luminal stenosis),
Non-obstructive (plaques with a lumen narrowing $<50 \%$ ), or obstructive (plaques with maximum stenosis $>50 \%$ ). Diagnosis of $\mathrm{CAD}$ will be made based on the maximum intra-luminal stenosis in any of the segments of the major epicardial coronary arteries at the $>50 \%$ stenosis threshold.

- Obstructive CAD in the diagonal branches, obtuse marginal branches and posterolateral branches will be a part of the left anterior descending (LAD) artery, left circumflex (LCX) artery, and right coronary artery (RCA) system, respectively. Depending on the coronary artery dominance, the posterior descending artery will be a part of the RCA or LCX system ${ }^{(9)}$.

- For each patient, the number of diseased vessels will be calculated through the assignation of one, two, three, or left main coronary artery vessels. Coronary artery calcium scoring will be performed using gated non-contrast images acquired prior to CT angiography. Using the Agatston method, calcium detection and quantification will be performed by an electrocardiographically triggered, sequential step and shoot acquisition mode (10).

- Coronary artery calcium will be identified as a dense area in the coronary artery exceeding the threshold of $130 \mathrm{HU}$. MSCT coronary angiography will be analyzed by an experienced operator.

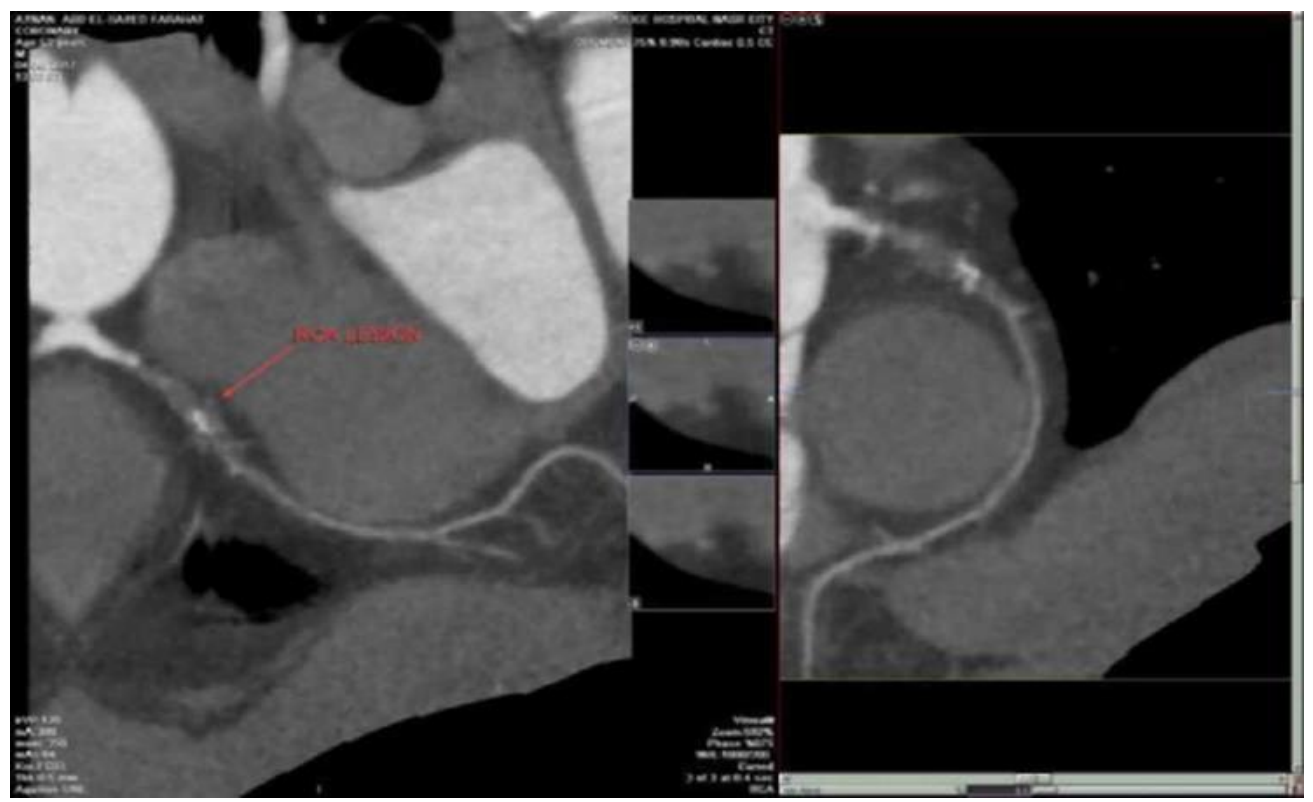

Figure (1): Example of a patient with significant CAD at proximal RCA. 


\section{Carotid Doppler ultrasonography:}

- To measure intima media thickness color Doppler and pulse Doppler ultrasonography of both carotid arteries will be performed with an ultrasound machine (Esaote MYLAB TM X vision) equipped with a $12-5-\mathrm{MHz}$ linear array transducer. Patients will be examined in the supine position with the head tilted backwards. After location of the carotid arteries by transverse scans the probe will be rotated 90 to obtain and record a longitudinal image of the anterior and posterior walls.

- Although atherosclerosis and CIMT progress more rapidly in the bulb and internal carotid segments, limiting CIMT measurements to the far wall of the CCA is the preferred strategy for clinical testing, as stated in most guidelines for CIMT measurement ${ }^{\text {(11). }}$.

- All measurements of carotid IMT will be made by a single operator. According to the American Society of Echocardiography three carotid IMT measurements will be made in distal common carotid arteries, at the bifurcation and proximal internal carotid arteries. Upper normal average IMT is estimated to be up to $0.9 \mathrm{~mm}^{(\mathbf{1 2})}$.

\section{Statistical analysis:}

Statistical analysis was performed using the Statistical Package for Social Sciences version 16.0 (SPSS for Windows 16.0, Inc., Chicago, IL, USA).

Regarding quantitative parameters, the data was tested for normality using Shapiro wilk test that revealed that data was not normally distributed. So, nonparametric tests were used. Results were expressed as Median (Q1-Q3). MannWhitney test was used to compare one variable in two groups. Kruskal Wallis test was used to compare one variable in more than two groups.

Categorical data are presented as absolute numbers and percentages within brackets. A $\% 2$ analysis or Fisher exact test was used to compare these variables when expected cell frequency was less than five.

Correlations between nonparametric data are done using spearman correlation coefficient.

All $\mathrm{P}$ values were based on a 2-tailed distribution, and the corresponding $\mathrm{P}$ value:

- Non-significant (NS) difference if $\mathrm{P}>$ 0.05 .

- Significant(S) difference if $\mathrm{P}<0.05$.

- Highly significant (HS) difference if $\mathrm{P}<$ 0.001 .

The statistical analysis was based on the intentionto-treat population.

\section{RESULTS}

The study enrolled 39 patients whose data has been collected since June 2017 and until April 2018 who divided into three equal groups according to HbA1c:

Group A (Non-diabetics): 13 cases whose HbA1c $<5.7 \%$

Group B (Pre-diabetics): 13 cases whose HbA1c $5.7-6.4 \%$

Group c (Diabetics): 13 cases whose HbA1c $>=6.4 \%$

\section{Demographic data and risk factors}

Regarding demographic data and risk factors; there were significant difference among groups as regarding age, gender and dyslipidaemia. Age of patients in Group $\mathrm{C}$ was higher than that of group A and group B. Group B and C had more male patients than group A. Also, Dyslipidaemia was more prevalent in group C. No significant difference could be picked at level of smoking and hypertension. Details of demographic data and risk factors are presented in Table 1.

Table (1): Demographic data and risk factors of study population

\begin{tabular}{|c|c|c|c|c|c|c|}
\hline & $\begin{array}{c}\text { Group A } \\
\mathrm{N}=13\end{array}$ & $\begin{array}{c}\text { Group B } \\
\mathrm{N}=13\end{array}$ & $\begin{array}{c}\text { Group C } \\
\mathrm{N}=13\end{array}$ & Test value & $P$ value \\
\hline \multicolumn{2}{|l|}{ Age } & $\begin{array}{c}42 \pm 7.9 \\
39(32-53)\end{array}$ & $\begin{array}{l}47.9 \pm 6.3 \\
47(40-61)\end{array}$ & $\begin{array}{c}56.4 \pm 10.3 \\
57(43-78)\end{array}$ & $12.087^{\mathrm{KW}}$ & $0.002(\mathrm{~S})$ \\
\hline \multirow{2}{*}{ Gender } & Male & $6(46.2 \%)$ & $11(84.6 \%)$ & $11(84.6 \%)$ & \multirow{2}{*}{$6.331^{\mathrm{x} 2}$} & \multirow{2}{*}{$0.042(\mathrm{~S})$} \\
\hline & Female & $7(53.8 \%)$ & $2(15.4 \%)$ & $2(15.4 \%)$ & & \\
\hline \multicolumn{2}{|c|}{ Smoking } & $5(38.5 \%)$ & $8(61.5 \%)$ & $7(53.8 \%)$ & $1.437^{\times 2}$ & $0.488(\mathrm{NS})$ \\
\hline \multicolumn{2}{|c|}{ Hypertension } & $8(61.5 \%)$ & $9(69.2 \%)$ & $9(69.2 \%)$ & $0.231^{\mathrm{x} 2}$ & $0.891(\mathrm{NS})$ \\
\hline \multicolumn{2}{|c|}{ Dyslipidaemia } & $3(23.1 \%)$ & $6(46.2 \%)$ & $11(84.6 \%)$ & $10.058^{\mathrm{x} 2}$ & $0.007(\mathrm{~S})$ \\
\hline \multicolumn{2}{|c|}{$\mathrm{HB}$ A1C } & $\begin{array}{c}5 \pm 0.3 \\
4.9(4.6-5.5)\end{array}$ & $\begin{array}{c}6.1 \pm 0.2 \\
6.1(5.8-6.3)\end{array}$ & $\begin{array}{c}7.3 \pm 0.5 \\
7.2(6.5-8.3)\end{array}$ & & \\
\hline
\end{tabular}


Age distribution in study group (Group A average age was 42 with the youngest aged 32 and the oldest aged 53 while group B's average age was 47 with the youngest aged 40 and the oldest aged 61 , and group $\mathrm{C}$ average age was 57 with the youngest aged 43 and the oldest aged 78).

Gender distribution in study population (Group A included 7 females and 6 males while each of both groups B and C included 11 males and 2 females).

HB A1c levels in study groups (HB A1c levels for group A ranged between 4.6 and 5.5 averaging at 5 while for group B, it ranged between 5.8 and 6.3 with the average of 6.1 and for group $C$ the HB A1c averaged between 6.5 and 8.3 with median of 7.2).

\section{Multi-slice CT findings}

At level of multi-slice CT coronary, CCS was significantly higher in group $\mathrm{C}$ than in group $A$ and $B$. But no significant difference could be picked in subgroup analysis between group A and group B. There were no significant differences among groups as regarding significant coronary artery stenosis. But there was a trend towards significance in group $\mathrm{C}$; however, it failed to reach significance mostly because of the small sample size. At level of carotid Doppler US, there were significant differences between groups as regarding bilateral CIMT. But this significance was mainly between group $\mathrm{C}$ and the other groups in subgroup analysis. Details of Multi-slice CT and CIMT are presented in table 2.

Table (2): Multi-slice CT findings in the study groups

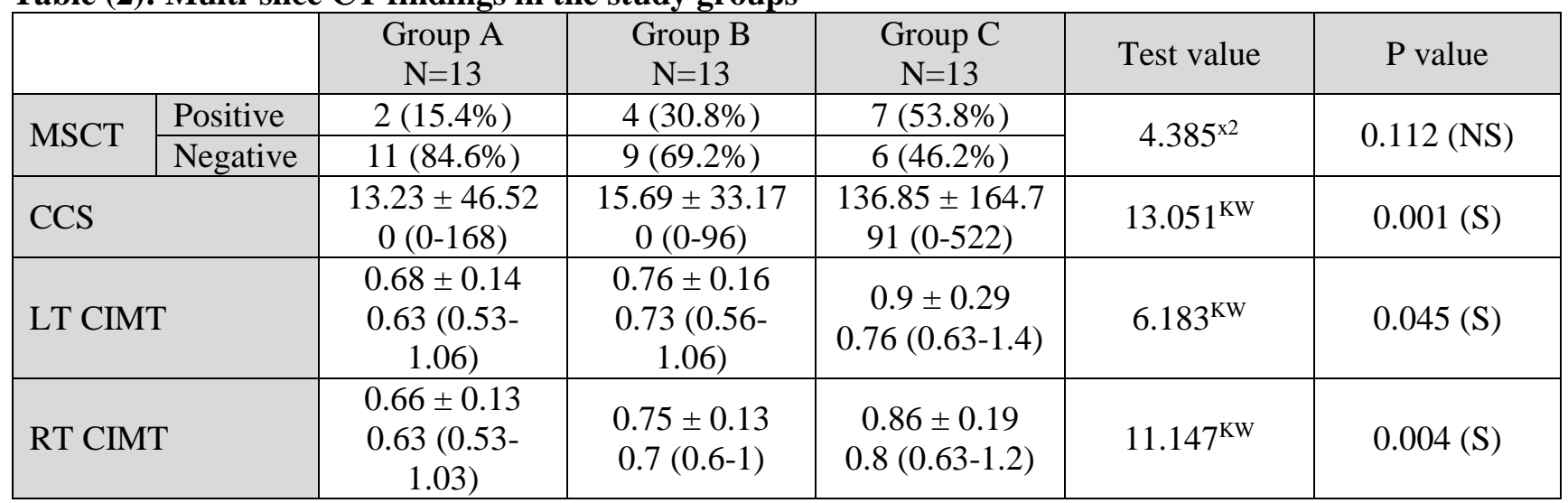

Table (3): subgroup comparison as regarding LT CIMT

\begin{tabular}{|l|l|l|}
\hline Post hoc & Group B & Group C \\
\hline Group A & $0.140(\mathrm{NS})$ & $0.020(\mathrm{~S})$ \\
\hline Group B & & $0.197(\mathrm{NS})$ \\
\hline
\end{tabular}

Table (4): Subgroup comparison as regarding RT CIMT

\begin{tabular}{|l|l|l|}
\hline Post hoc & Group B & Group C \\
\hline Group A & $0.030(\mathrm{~S})$ & $0.002(\mathrm{~S})$ \\
\hline Group B & & $0.105(\mathrm{NS})$ \\
\hline
\end{tabular}

Table (5): Subgroup comparison as regarding CCS

\begin{tabular}{|l|l|l|}
\hline Post hoc & Group B & Group C \\
\hline Group A & $0.405(\mathrm{NS})$ & $0.002(\mathrm{~S})$ \\
\hline Group B & & $0.005(\mathrm{~S})$ \\
\hline
\end{tabular}




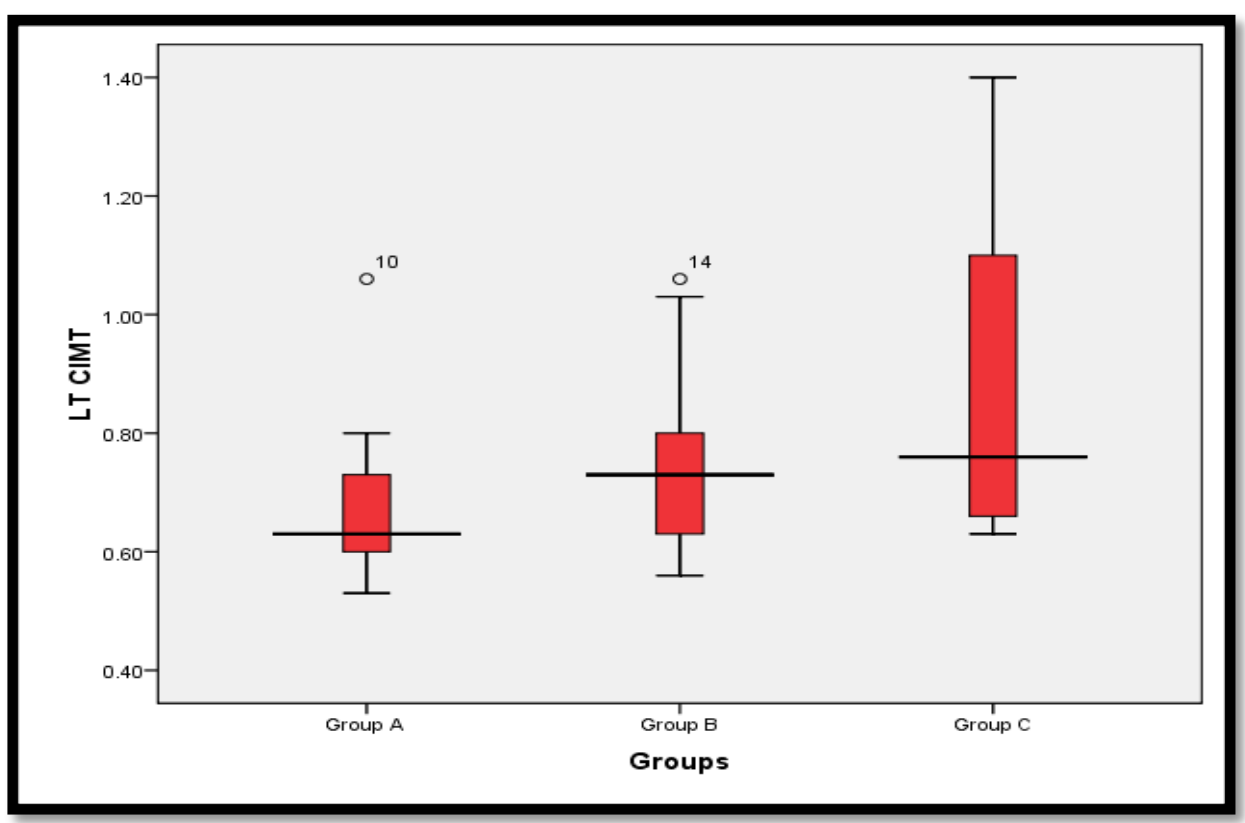

Figure (2): LT CIMT in study groups (The average for group A was 0.63 ranging between 0.53-1.06 while for group B, it was 0.73 ranging between 0.56-1.06, and in group $\mathrm{c}$ it ranged between 0.63-1.4 with average of 0.76 )

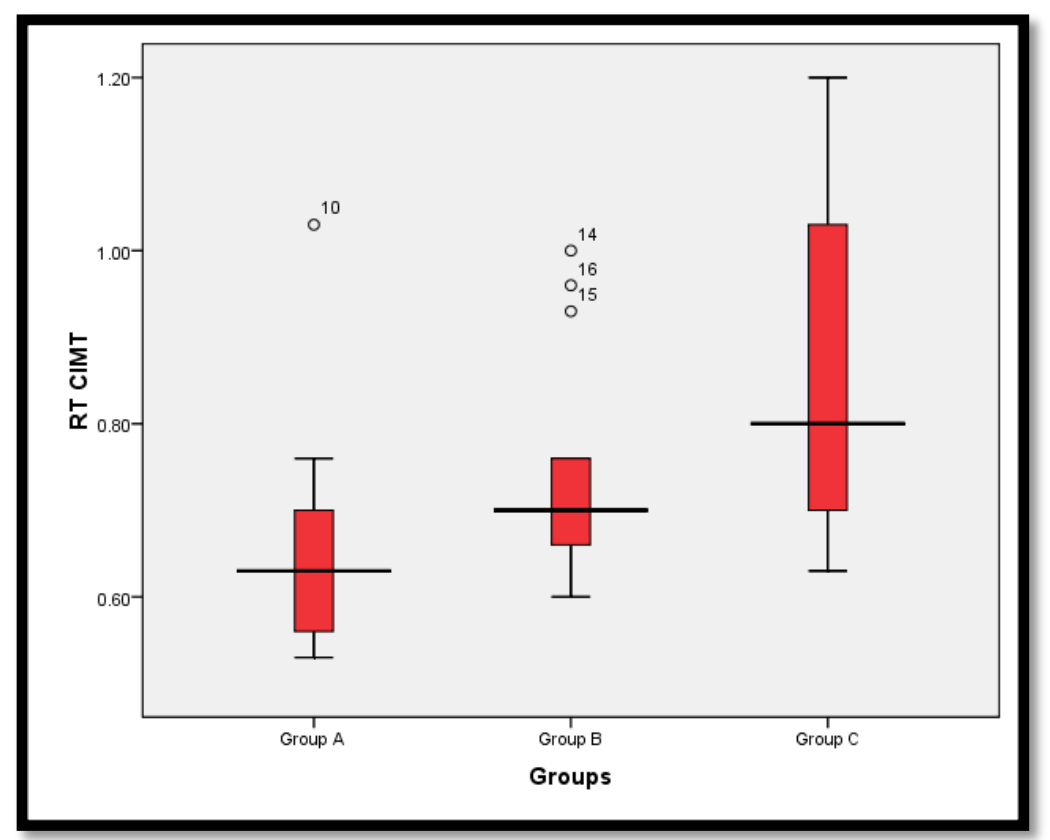

Figure (3): RT CIMT in study groups (The average for group A was 0.63 ranging between 0.53-1.03 while for group B, it was 0.7 ranging between $0.6-1$, and in group $\mathrm{c}$ it ranged between $0.63-1.2$ with average of $0.8)$.

\section{Correlations}

Table (6): Spearman correlation between CCS, CIMT, age, and HbA1C

\begin{tabular}{|c|c|c|c|c|c|}
\hline & & & LT CIMT & RT CIMT & CCS \\
\hline \multirow{4}{*}{ Spearman's rho } & \multirow{2}{*}{ Age (years) } & $\mathbf{R}$ & 0.675 & 0.682 & 0.375 \\
\hline & & P value & $<0.001$ (HS) & $<0.001$ (HS) & 0.019 (S) \\
\hline & \multirow{2}{*}{ HbA1c } & $\mathbf{R}$ & 0.503 & 0.635 & 0.618 \\
\hline & & P value & $0.001(\mathrm{~S})$ & $<0.001$ (HS) & $<0.001$ (HS) \\
\hline
\end{tabular}

As regarding correlation, age and HbA1c had a positive strong correlation with CCS, LT CIMT, and RT CIMT. Details of correlation in table 6. 


\section{DISCUSSION}

There is a scarcity in the published literature which examines whether HbAlc levels are associated with increased risk of atherosclerosis in population with normal fasting glucose. Therefore, we performed the present prospective study to assess whether $\mathrm{HbAlc}$ level, in apparently healthy nondiabetic subjects, is associated with coronary artery disease and carotid artery disease independent of traditional cardiovascular risk factors.

The present study included 39 patients who were divided into non-diabetics, pre-diabetics, and diabetics groups according to $\mathrm{HbAlC}$. The analysis showed that diabetic patients were more likely to be older, males, and dyslipidemic. Dyslipidaemia is a common feature of diabetes and there is an association between atherosclerotic cardiovascular disease and serum cholesterol and triglyceride levels in both types of diabetes ${ }^{(\mathbf{1 3})}$.

According to Mitiia et al. ${ }^{(14)}$, almost half of T2DM patients do not reaching their LDL-C goal. Strikingly, a recent survey by Sarfraz and colleagues showed that the prevalence of dyslipidaemia among diabetic males was $97.18 \%$ while for females $87.15 \%$ (156). While our study showed that the prevalence of dyslipidaemia among diabetics $84.6 \%$ and among prediabetics $46.2 \%$.

The coronary artery calcium score (CCS), studied mainly by multi-detector computed tomography (MDCT), plays an important role in cardiovascular risk stratification, which showed a significant association with the medium- or long-term occurrence of major cardiovascular events ${ }^{(\mathbf{1 5})}$. While Carotid intima media thickness (CIMT) is used commonly as a non-invasive test for the assessment of degree of atherosclerosis ${ }^{\left({ }^{16}\right)}$. In the present study, we used CCS and CIMT as surrogate markers for coronary and carotid atherosclerosis.

In our study as expected, patients with T2DM had statistically significant higher CCS (136.85 \pm $164.7 \mathrm{p}$-value <0.001) and CIMT scores $(0.9 \pm 0.29$ $\mathrm{p}$-value $=0.045$ and $0.86 \pm 0.19 \mathrm{p}$-value $=0.004$, for LT and RT CIMT respectively) than pre-diabetics and healthy controls. Notably, pre-diabetic individuals showed a statistically significant higher right CIMT score $(0.75 \pm 0.13 \mathrm{p}$-value $<0.03)$ than healthy controls $(0.66 \pm 0.13)$.

However, there were no significant differences between both groups in terms of left CIMT (P-value $=0.140$ ). Similar to our findings, Mukai et al. ${ }^{(17)}$ performed a cross-sectional study on 2702 subjects to assess the associations of HbAlc CIMT in community-dwelling Japanese subjects. The results showed a statistically significant higher CIMT scores in patients with glucose intolerance by HbAlc, GA, FPG, and 2-hour PG levels compared to normal controls (all $\mathrm{p}$ for trend $<0.05$ ), but not 2-hour PG ( $\mathrm{p}$ $=0.07$ ).

Similarly, Ma et al. ${ }^{(18)}$ investigated the correlations of glycated haemoglobin Ale (HbAlc) and glycated albumin (GA) with subclinical atherosclerosis in middle-aged and elderly Chinese populations including 640 patients with impaired glucose regulation. They reported that $\mathrm{HbAlc}$ and glycated albumin were significantly higher in subjects with increased CIMT than in subjects with normal CIMT. Correlation analysis showed that both HbAlc and GA were positively correlated with C-IMT ( $\mathrm{r}=$ 0.135 and 0.112 , respectively; both $\mathrm{P}<0.01$ ).

About our primary outcomes, the analysis showed a statistically significant positive correlation between HbAlc and coronary atherosclerosis, measured by CCS $(r=0.618, p<0.001)$, However with no difference between pre-diabetic and non-diabetic groups. In concordance with our findings, Carson et al. ${ }^{(19)}$ conducted a prospective study on 2, 076 nondiabetic participants to investigate the association of HbAlc with CCS progression. The results showed a statistically significant positive correlation between $\mathrm{HbAlc}$ and CCS, higher HbAlc was independently associated with advanced CAC progression among individuals without diabetes.

However, Scicali et al. (20) performed a prospective cohort study to examine the association between HbAlc and coronary calcification. The CCS score was higher in the prediabetic group compared to non-diabetic subjects $(\mathrm{p}<0.001)$. The logistic regression showed that higher $\mathrm{HbAlc}$ levels were associated with CCS. In addition, Xing et al. (21) reported that those with prediabetes by HbAlc versus normal HbAlc had more CCS. Mesquita et al. ${ }^{(22)}$ reported a statistically significant association between CCS and HbAlc. Notably, the present study didn't show the same mostly due to the small sample size.

The current body of evidence suggests a significant association between $\mathrm{HbAlc}$ levels and the severity of CAD as well. Kaya et al. ${ }^{(23)}$ conducted their study on 93 patients undergoing coronary angiography to find the relationship between the severity of the coronary artery disease measured with the Gensini score and the hemoglobin Ale (HbAlc) levels in non-diabetic patients. They reported that the $\mathrm{HbAlc}$ values were significantly higher in severe atherosclerosis group compared with mild atherosclerosis and normal coronary arteries $(6.7 \pm 1.5$, $6.0 \pm 0.8$ and $5.6 \pm 0.6 \%$, respectively, $\mathrm{p}=0.002$ ). A cutoff value of $6.0 \%$ for HbAlc predicted severe atherosclerosis with a sensitivity and specificity of $54 \%$ and $74 \%$, respectively. Moreover; the HbAlc values were observed to be correlated with the Gensini score ${ }^{(23)}$.

Our analysis showed that HbAlc had a positive strong correlation with CIMT as well, for the 
Rt CIMT and Lt CIMT ( $\mathrm{p}=0.004$ and $\mathrm{p}=0.045$, respectively). In agreement with these findings, the Korean Urban Rural Elderly study, which was conducted on 1, 133 participants. They had fasting blood glucose less than $100 \mathrm{mg} / \mathrm{dL}(5.6 \mathrm{mmol} / \mathrm{L})$ and HbAlc level below $6.5 \%$ (48 $\mathrm{mmol} / \mathrm{mol})$. They were also free from a history of cardiovascular disease. This study reported that HbAlc levels were positively associated with carotid atherosclerosis, as assessed by carotid IMT ( $\mathrm{P}=0.020, \mathrm{p}=0.045)$, in an elderly population with normoglycen ${ }^{(24,25)}$.

Similarly, Ma et al. ${ }^{(\mathbf{1 8})}$ reported that HbAlc was positively correlated with CIMT, the logistic regression analysis revealed that $\mathrm{HbAlc}$ was independent risk factors for increased CIMT" $16^{\wedge}$. HbAlc was reported to be significantly associated with CIMT independent of conventional cardiovascular risk factors in another study.

We acknowledge that the present study has several limitations. The sample size of the present study was relatively small which may affect the generalizability of our findings. In addition, the patients were not followed up to assess the long-term consequences of elevated HbAlc on CVS risk.

In conclusion, HbAlc positively correlates with coronary and carotid atherosclerosis and patients with mild elevation of HbAlc has significantly more CIMT than individuals with normal HbAlc. Higher HbAlc level may be used as effective and informative marker of carotid and coronary atherosclerosis, however, further long-term studies are still needed to confirm these findings.

\section{CONCLUSION}

The coronary calcification and carotid intima media thickness are positively correlated to abnormal HbAlc levels. We, therefore, recommend that patients without history of DM and with positive HbAlc to be sent for CIMT assessment. Besides, those having the same criteria who are indicated for MSCT are expected to have higher CCS.

\section{REFERENCES}

1. American Diabetes Association (2010): Diagnosis and classification of Diabetes Mellitus. Diabetes Care, 33(1):6269.

2. International Expert Committee (2009): International Expert Committee report on the role of Ale assay in the diagnosis of diabetes. Diabetes Care, 32: 1327-1334.

3. World Health Organization (2011): Use of Glycated Hemoglobin (HbAlc) in the diagnosis of Diabetes Mellitus. Who/nhm/chp/cpm/11.

4. American Diabetes Association (2012): Standards of medical care in diabetes. Diabetes Care, 1: 13-61.

5. Libby $\mathbf{P}$, Ridker PM, Maseri A (2002): Inflammation and atherosclerosis. Circulation, 105:1135-43.

6. Mullet NR, Cademartiri F, van Mieghem CA, Runza G, McFadden EP, Baks T, Serruys PW, Krestin GP and de Feyter PJ (2005): High-resolution spiral computed tomography coronary angiography in patients referred for diagnostic conventional coronary angiography. Circulation, 112(15): 2318-23.

7. O'leary DH, Polak JF, Kronmal RA, Manolio TA, Burke GL, Wolfson SK (1999): Carotid-artery intima and media thickness as a risk factor for myocardial infarction and stroke in older adults. New England Journal of Medicine, 340(1): $14-22$.

8. Giral R, Martinez-Salamero L, Singer $S$ (1999): Interleaved converters operation based on CMC. IEEE Transactions on Power Electronics, 14(4): 643-52.

9. Raff GL, Abidov A, Achenbach S, Berman DS, Boxt LM, Budoff MJ, Cheng V, DeFrance T, Hellinger JC, Karlsberg RP (2009): SCCT guidelines for the interpretation and reporting of coronary computed tomographic angiography. Journal of Cardiovascular Computed Tomography, 3(2): 122-36.

10. Agatston AS, Janowitz WR, Hildner FJ, Zusmer NR, Viamonte M, Detrano R (1990): Quantification of coronary artery calcium using ultrafast computed tomography. Journal of the American College of Cardiology, 15(4): 827-32.

11.Simova I (2015): Intima-media thickness: appropriate evaluation and proper measurement, described. E-Journal Cardiol Pract., 13: 21-26.

12. Celik S, Erdogan T, Kasap H, Kaplan S, Durmus I, Gedik O, Kins A (2007): Carotid intima-media thickness in patients with isolated coronary artery ectasia. Atherosclerosis, 190(2): 385-7.

13. Howard B V, Robbins DC, Sievers ML, Lee ET, Rhoades D, Devereux RB, Cowan LD, Gray RS, Welty TK, Go OT, Howard WJ (2000): LDL cholesterol as a strong predictor of coronary heart disease in diabetic individuals with insulin resistance and low LDL: the Strong Heart Study. Arterioscler Thromb Vase Biol., 20: 830-835.

14. Mithal A, Majhi D, Shunmugavelu M, Talwarkar PG, Vasnawala $H$ and Raza AS (2014): Prevalence of dyslipidaemia in adult Indian diabetic patients: A cross sectional study (SOLID). Indian J Endocrinol Metab., 18: 642-7.

15. Nevesl PO, Joalbo AHM, Neves PO, Andrade J, Moncao H (2017): Coronary artery calcium score: current status. Radiol Bras., 50: 182-189.

16. O'Leary DH, Polak JF, Kronmal $R$ a, Manolio $T$ a, Burke GL, Wolfson SK (1999): Carotid-artery intima and media thickness as a risk factor for myocardial infarction and stroke in older adults. N Engl J Med., 340: 14-22.

17. Mukai N, Ninomiya T, Hata J, Hirakawa Y, Ikeda F, Fukuhara M, Hotta T, Koga M, Nakamura U, Kang D, Kitazono T, Kiyohara Y (2015): Association of hemoglobin Alcand glycated albumin with carotid atherosclerosis in community-dwelling Japanese subjects: The Hisayama Study. Cardiovasc Diabetol., 14: 84-88.

18. Ma X, Shen Y, Hu X, Hao Y, Luo Y, Tang J, Zhou J, Bao Y, Jia W (2015): Associations of glycated hemoglobin Ale and glycated albumin with subclinical atherosclerosis in middle-aged and elderly Chinese population with impaired glucose regulation. Clin Exp Pharmacol Physiol., 42: 582587.

19. Carson AP, Steffes MW, Carr JJ, Kim Y, Gross MD, Carnethon MR, Reis JP, Loria CM, Jacobs DR, Lewis CE, Lewis CE (2015): Hemoglobin ale and the progression 
of coronary artery calcification among adults without diabetes. Diabetes Care, 38: 66-71.

20.Scicali R, Giral P, Gallo A, Di Pino A, Rabuazzo AM, Purrello F, Cluzel P, Redheuil A, Bruckert E, Rosenbaum D (2016): HbAlc increase is associated with higher coronary and peripheral atherosclerotic burden in non-diabetic patients. Atherosclerosis, 255: 102-108.

21.Xing FY, Neeland IJ, Gore MO, Ayers CR, Paixao AR, Turer AT, Berry JD, Khera A, de Lemos JA, McGuire DK (2014): Association of prediabetes by fasting glucose and/or haemoglobin Ale levels with subclinical atherosclerosis and impaired renal function: Observations from the Dallas Heart Study. Diabetes Vase Dis Res., 11: 1118.

22. Mesquita PN, Dornelas Leao Leite AP, das Chagas Crisostomo S, Veras Filho E, da Cunha Xavier L, Bandeira F (2017): Evaluation of coronary calcium score in patients with normocalcemic primary hyperparathyroidism. Vase Health Risk Manag., 13: 225-229.

23. Kaya H, Ertas F, Oylumlu M, Akil MA, Alan S (2013): The Relationship of the Glycosylated Hemoglobin Ale Levels with the Severity of the Coronary Artery Disease in Non-diabetic Stable Angina Patients. J Am Coll Cardiol., 62: 211-18.

24.Lee SW, Kim HC, Lee Y-H, Song BM, Choi H, Park JH, Rhee Y, Kim CO (2017): Association between HbAlc and carotid atherosclerosis among elderly Koreans with normal fasting glucose. PLoS One, 12: 171761.

25.Huang Y, Bi Y, Wang W, Xu M, Xu Y, Li M, Wang T, Chen Y, Li X, Ning G (2011): Glycated Hemoglobin Ale, Fasting Plasma Glucose, and Two-Hour Post challenge Plasma Glucose Levels in Relation to Carotid Intima-Media Thickness in Chinese with Normal Glucose Tolerance. J Clin Endocrinol Metab., 96: 1461-1465. 